\begin{tabular}{|c|c|}
\hline Postprint Version & 1.0 \\
\hline Journal website & http://www.blackwell-synergy.com \\
\hline Pubmed link & $\begin{array}{l}\text { http://www.ncbi.nlm.nih.gov/entrez/query.fcgi?cmd=Retrieve\&db=pubmed\&dop } \\
\mathrm{t}=\text { Abstract\&list uids=16433791\&query hl=13\&itool=pubmed docsum }\end{array}$ \\
\hline DOI & 10.1111/j.1365-2133.2005.06766.x \\
\hline
\end{tabular}

\title{
Impetigo: incidence and treatment in Dutch general practice in 1987 and 2001-results from two national surveys
}

\author{
S. KONING, R.S.A. MOHAMMEDAMIN, J.C. VAN DER WOUDEN, L.W.A. VAN SUIJLEKOM-SMIT,* F.G. \\ SCHELLEVIS_AND S. THOMAS

 \\ CENTRE ROTTERDAM, PO BOX 1738, 3000 DR ROTTERDAM, THE NETHERLANDS
}

NETHERLANDS INSTITUTE FOR HEALTH SERVICES RESEARCH, UTRECHT, THE NETHERLANDS

\section{SUMMARY}

Background Impetigo is a common skin infection in children. The epidemiology is relatively unknown, and the choice of treatment is subject to debate.

Objective The objective of our study was to determine the incidence and treatment of impetigo in Dutch general practice, and to assess trends between 1987 and 2001.

Methods We used data from the first (1987) and second (2001) Dutch national surveys of general practice. All diagnoses, prescriptions and referrals were registered by the participating general practitioners (GPs), 161 and 195, respectively.

Results The incidence rate of impetigo increased from 16.5 (1987) to 20.6 (2001) per 1000 person years under 18 years old $(\mathrm{P}<0 \cdot 01)$. In both years, the incidence was significantly higher in summer, in rural areas and in the southern region of the Netherlands, compared with winter, urban areas and northern region, respectively. Socioeconomic status was not associated with the incidence rate. From 1987 to 2001, there was a trend towards treatment with a topical antibiotic (from 43\% to 64\%), especially fusidic acid cream and mupirocin cream. Treatment with oral antibiotics (from $31 \%$ to $14 \%$ ) and antiseptics (from $11 \%$ to 3\%) was prescribed less often.

Conclusions We have shown an increased incidence of impetigo in the past decade, which may be the result of an increased tendency to seek help, or increased antibiotic resistance and virulence of Staphylococcus aureus. Further microbiological research on the marked regional difference in incidence may contribute to understanding the factors that determine the spread of impetigo. Trends in prescribing for impetigo generally follow evidence-based knowledge on the effectiveness of different therapies, rather than the national practice guideline.

Impetigo or impetigo contagiosa is a relatively harmless superficial skin infection, usually treated by general practitioners. ${ }^{1}$ Staphylococcus aureus is currently the most common causative agent. Although the incidence and population prevalence of impetigo seem to have decreased over past decades, it is still a common disease, particularly in young children. ${ }^{1-3}$

Not much is known about the epidemiology. There is a general belief that good hygiene may prevent the occurrence of impetigo, ${ }^{4}$ and that social factors such as crowding may increase the risk of developing this disease. Regarding the level of the pathogen, specific characteristics of S. aureus have been identified which affect the development and course of impetigo. ${ }^{5-7}$ 
There is debate about the treatment of impetigo. Are topical antibiotics effective? Should their use be promoted or discouraged because of rising resistance rates, especially against fusidic acid? ${ }^{8,9}$ Since 1999, there has been a Practice Guideline on bacterial skin infections for Dutch general practitioners (GPs), issued by the Dutch College of General Practitioners (NHG). ${ }^{10}$ The 80 NHG Practice Guidelines are primarily based on evidence and, in areas where evidence is absent, on consensus. In summary, the advice for impetigo is a basic treatment with disinfection, and additional zinc ointment in patients with limited lesions, or fusidic acid cream in case of more extensive lesions.

Against the background of changing social behaviour and changing bacterial resistance it is important to establish the occurrence and treatment of impetigo in daily practice. We investigated the incidence of impetigo and its management by GPs in the Netherlands, and tried to identify trends between 1987 and 2001. Our questions were: (i) How often does the GP see patients aged 0-17 years with impetigo, how is the incidence related to sex, age, season, region, urbanization level and socioeconomic status, and how did that change between 1987 and 2001? (ii) What is the treatment policy of the GP, and how did that change between 1987 and 2001?

\section{METHODS}

We analysed data from the first and second Dutch national surveys of general practice, which were carried out by the Netherlands Institute for Health Services Research in 1987 and 2001, respectively. Ethical approval was obtained and privacy regulations were in agreement with the Dutch legislation. For this study, data from both surveys for patients aged $0-17$ years were analysed. In the Netherlands, general practices have a fixed list size, and all noninstitutionalized inhabitants are listed in a general practice; GPs have a gate-keeping role. Both surveys included a representative sample of the Dutch population, according to age, sex and insurance status. The participating GPs were representative for age and sex. The practices in both surveys were representative for region and urbanization level, but single-handed practices were underrepresented.

\section{First Dutch National Survey 1987}

A nonproportionally stratified sample of 161 GPs was selected randomly to participate in the survey. The GPs were divided into four groups and each group registered data on registration forms for all contacts between patient and practice during one of four consecutive 3-month periods during 1987. The four registration periods covered one calendar year to correct for seasonal variability of morbidity. Data recorded from each consultation included patient characteristics (age, sex), diagnosis and prescription of drugs. Specially trained workers used the International Classification of Primary Care (ICPC) to code diagnoses made by the GP. Other demographic patient characteristics were obtained by a questionnaire. Because of an under-representation of deprived areas, the population was weighted according to the Dutch population of 1987. For further details about the first Dutch national survey, we refer to the book by Bruijnzeels et al. ${ }^{1}$

\section{Second Dutch National Survey 2001}

The second national survey was carried out in 2001. In short, 195 GPs in 104 practices registered data about all physician- patient contacts during 12 months. GPs registered all health problems presented within a consultation and coded diagnoses using the ICPC. Also, all prescriptions made by the GP were registered. Characteristics of participating practices such as location in a rural or urban area were obtained by mailed questionnaire. Patient characteristics such as age and sex were derived from the GPs' computerized patient files. For further details about the second Dutch national survey, we refer to the article by Westert et al. ${ }^{11}$ For this analysis, data from nine of the 104 practices (10 GPs) were excluded for various reasons: five practices with inadequate registration of patient contacts or drug prescription were excluded after quality control. Four other practices were excluded because of software problems.

Both surveys were episode oriented, meaning that different consultations concerning the same health problem are linked to one episode. A consultation concerning a new health problem marks the beginning of a new episode. If there were several consultations in a single episode, the last diagnosis made is considered the diagnosis of the episode. Out-of-hours consultations were also registered. 


\section{Statistical analyses}

We defined incidence as the number of first contacts for impetigo per 1000 person years. Differences between incidence rates were tested, assuming a Poisson distribution with a significance level of 0·05, using STATA version 8.2 (Stata Corp., College Station, TX, U.S.A.).

\section{RESULTS}

In the first National Survey (1987) and the second National Survey (2001), 86577 and 82053 patients aged 0-17 participated, respectively. In these groups, there were 357 (1987) and 1682 (2001) episodes of impetigo. These figures form the basis of the incidence rates.

\section{Incidence}

The incidence of impetigo in people under 18 years old was 16.5 per 1000 person years in 1987. In 2001 , the incidence had risen to $20 \cdot 6$, an increase of $25 \%$ ( $\mathrm{P}<0 \cdot 01)$. The incidence by age is represented in Figure 1. In particular, it shows that children aged 6-11 years had impetigo more often in 2001 compared with 1987. Consequently, the peak age group for impetigo has widened and shifted to an older age. There was no sex difference in incidence in both surveys.

Table 1 shows the incidence of impetigo, related to the type of insurance, urbanization level, region, season and socioeconomic status. As in 1987, impetigo was more frequent in smaller towns and villages (<30 000 inhabitants). This difference was statistically significant compared with all three other categories of urbanization level. There was a geographical gradient in both surveys, stronger in 2001 than in 1987. In the south of the Netherlands, the incidence of impetigo was twice as high as in the north. On multivariate analysis, this proved to be independent of urbanization level. The seasonal peak in incidence in the summer was stronger in 2001 than in 1987. Socioeconomic and insurance status (sick fund or private insurance) appeared not to be a significant factor in either survey.

\section{[ TABLE 1 ]}

\section{[ FIGURE 1 ]}

\section{Prescriptions}

The data are based on the prescriptions given at the first contact of an episode, and are presented in Table 2. Seventy-four percent of all prescriptions in 1987 were for an antibiotic; in 2001 this was $78 \%$. In 2001, more topical antibiotics, especially fusidic acid cream and mupirocin cream, and fewer oral antibiotics were prescribed than in 1987. Other topical antibiotics were hardly used anymore. The number of prescriptions for antiseptic agents decreased from $11 \%$ to $3 \%$. In a small minority of the consultations more than one prescription was issued.

\section{DISCUSSION}

\section{Increased incidence}

The increased incidence we observe here may reflect a rising tendency of medical attention-seeking and should not necessarily imply an increase at population level. The unsightly aspect of (facial) impetigo may now be less acceptable to parents than before. Also, there seems to be more pressure from the school for the child to undergo antibiotic treatment before they can be permitted at school again. Possible explanations for an increased incidence at the population level are either a change in human behaviour, such as increased travelling or, alternatively, increasing virulence of S. aureus. The genetic characteristics of $\mathrm{S}$. aureus are changing, and selection of more virulent strains may be taking place. ${ }^{5}$ Also, a rise of antibiotic resistance in staphylococci has been reported. ${ }^{8,9,12,13}$ As a result, the cure of impetigo may take longer than before and patients may be contagious for a longer period. Reports of impetigo epidemics that are difficult to control, caused by multiple resistant staphylococci, are illustrative in this respect. ${ }^{14,15}$

\section{[ TABLE 2 ]}




\section{Regional variance in incidence}

The twofold higher incidence in the south compared with the north is striking, especially for a small country like the Netherlands. Climatic differences within the country are small and seem to offer no explanation. The level of urbanization and socioeconomic status turned out not to be a factor either, as shown by multivariate analysis. We propose that staphylococcal transfer from pigs to humans may explain the geographical gradient. There is a concentration of pig farming in the southern provinces of the country, where approximately 10 times as many pigs are bred as in the northern provinces. ${ }^{16}$ It has been shown recently that pig farmers in France were more frequently nasal carriers of S. aureus than matched nonfarmers, and that the S. aureus were more frequently macrolide resistant. ${ }^{17}$ Also, it has been demonstrated that pyogenic skin infection of people was caused by S. aureus of animal host origin. ${ }^{18}$

The same explanation may account for the twofold higher incidence of impetigo in rural areas compared with other urbanization levels, which was independent of region. Research comparing the genetic characteristics of staphylococcal specimens derived from different regions would be needed to test these hypotheses. The higher incidence of impetigo in the summer is not new and is consistent with many other reports. ${ }^{2,19,20}$

\section{Treatment}

There is a trend towards the prescription of topical antibiotics instead of oral antibiotics for impetigo. The increase in fusidic acid cream prescriptions may be influenced by the publication of the national practice guideline on bacterial skin infections in $1999 .{ }^{10}$ In this guideline, fusidic acid is the firstchoice antibiotic treatment. In contrast, the number of prescriptions of mupirocin has also increased. Mupirocin cream, which was not yet available in 1987, has proven efficacy in the treatment of impetigo, ${ }^{21}$ but was not recommended in the 1999 guideline, on the grounds that mupirocin should be reserved for the treatment of nasal carriage of S. aureus. Many GPs did not follow the guideline in this respect. Furthermore, the guideline recommends antiseptic therapy with chlorhexidine or povidoneiodine as a basic treatment. This advice was complied with even less often in 2001 than in 1987. A large proportion of GPs apparently have no faith in the value of antiseptic treatments. The lack of evidence for the effectiveness of antiseptics may play a role. ${ }^{21}$ It is remarkable that penicillinasesusceptible penicillins such as penicillin, amoxicillin and feneticillin are still often prescribed.

\section{Limitations of this study}

There are small differences in the design of the two national surveys, which might hinder the comparability of data. For example, in the first national survey, trained investigators coded diagnoses afterwards, whereas in the second national survey, the GPs coded the diagnoses themselves during the consultation. Furthermore, the participating GPs in the two national surveys may not be fully representative of the average GP in the Netherlands. This and the fact that their actions were recorded might distort our results.

In conclusion, we have shown an increased incidence of impetigo in the past decade, with marked regional differences in incidence. Further (microbiological) research on this observation may contribute to understanding the factors that determine the spread of impetigo. Second, we found variation in the treatment of impetigo by GPs, which was incompatible with the national guideline.

\section{ACKNOWLEDGMENTS}

The Dutch Ministry of Health, Welfare and Sports mainly funded the surveys directly or indirectly. In addition, the 'Stichting Centraal Fonds RVVZ' contributed financially to the second survey. 
S. Koning, R.S.A. Mohammedamin, J.C. van der Wouden, L.W.A. van Suijlekom-Smit, F.G. Schellevis, S. Thomas Impetigo: incidence and treatment in Dutch general practice in 1987 and 2001: results from two national surveys. British Journal of Dermatology: jrg. 154, 2006, p. 239-243

\section{TABLES AND FIGURES}

Fig 1. Incidence by age.

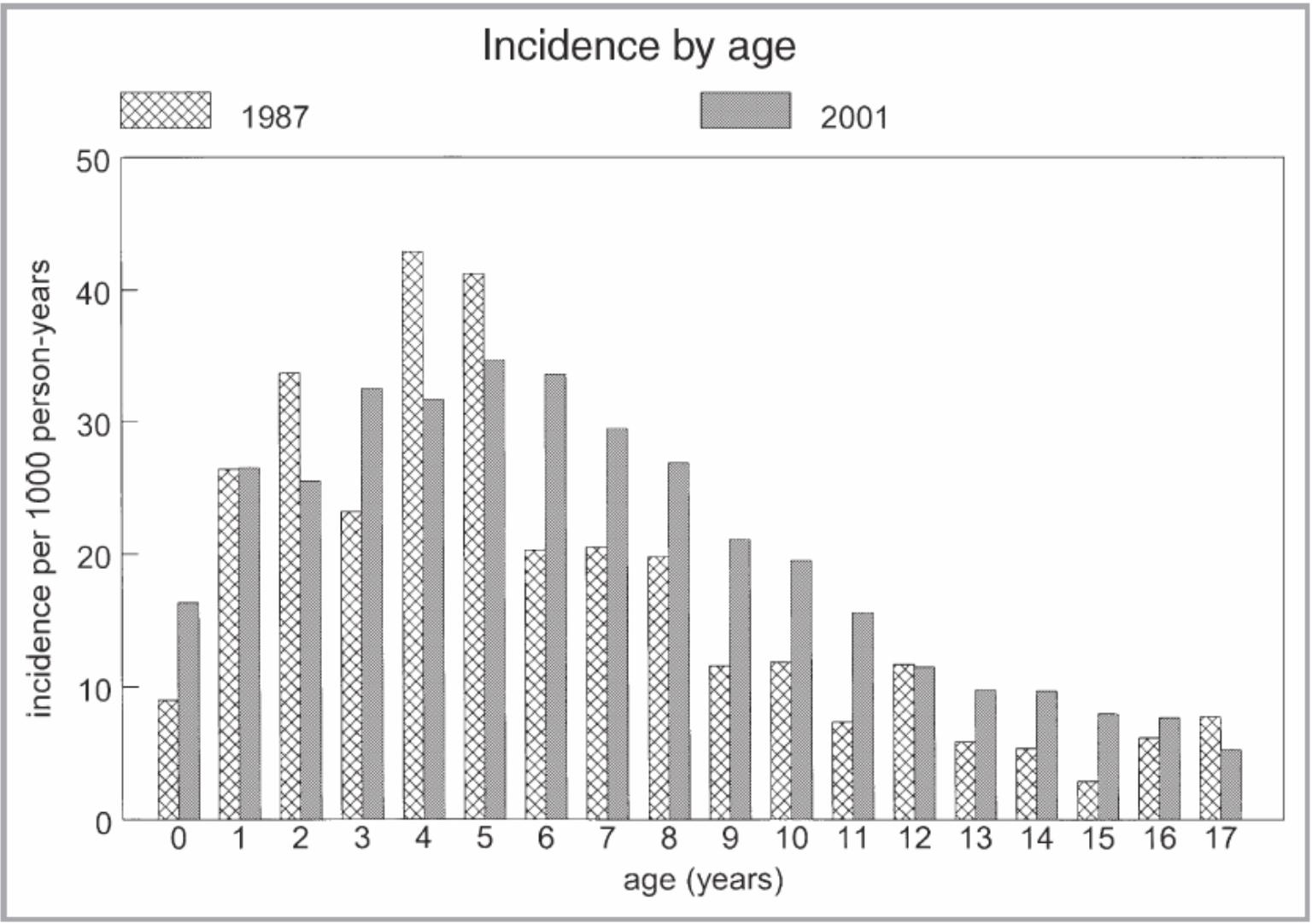

Table 1 Incidence of impetigo in people of $0-17$ years old, by urbanization level, region and season

\begin{tabular}{|c|c|c|c|c|}
\hline & \multicolumn{2}{|l|}{1987} & \multicolumn{2}{|l|}{2001} \\
\hline & $\begin{array}{l}\text { Incidence per } \\
1000 \text { person } \\
\text { years }(0-17)\end{array}$ & $95 \% \mathrm{CI}$ & $\begin{array}{l}\text { Incidence per } \\
1000 \text { person } \\
\text { years }(0-17)\end{array}$ & $95 \% \mathrm{CI}$ \\
\hline \multicolumn{5}{|l|}{ Urbanization level } \\
\hline$<30000$ inhabitants & $22 \cdot 0$ & $18 \cdot 8-25 \cdot 6$ & $27 \cdot 9$ & $26 \cdot 2-29 \cdot 7$ \\
\hline $30-50000$ inhabitants & $13 \cdot 7$ & $11 \cdot 3-16 \cdot 6$ & $13 \cdot 5$ & $11 \cdot 7-15 \cdot 5$ \\
\hline$>50000$ inhabitants & $14 \cdot 0$ & $10 \cdot 7-18 \cdot 0$ & $15 \cdot 7$ & $14 \cdot 3-17 \cdot 3$ \\
\hline Big cities $^{\mathrm{a}}$ & $11 \cdot 5$ & $7 \cdot 2-17 \cdot 4$ & $15 \cdot 9$ & $12 \cdot 7-19 \cdot 6$ \\
\hline \multicolumn{5}{|l|}{ Region } \\
\hline North & $15 \cdot 6$ & $11 \cdot 1-21 \cdot 5$ & $13 \cdot 4$ & $11 \cdot 4-15 \cdot 7$ \\
\hline Mid & $15 \cdot 5$ & $13 \cdot 5-17 \cdot 7$ & $19 \cdot 4$ & $18 \cdot 2-20 \cdot 7$ \\
\hline South & $19 \cdot 2$ & $15 \cdot 7-23 \cdot 3$ & $26 \cdot 3$ & $24 \cdot 3-28 \cdot 5$ \\
\hline \multicolumn{5}{|l|}{ Season } \\
\hline Winter & $15 \cdot 6$ & $12 \cdot 3-19 \cdot 6$ & $14 \cdot 8$ & $13 \cdot 2-16 \cdot 6$ \\
\hline Spring & $10 \cdot 9$ & $8 \cdot 5-13 \cdot 8$ & $12 \cdot 3$ & $10 \cdot 9-14 \cdot 0$ \\
\hline Summer & $21 \cdot 5$ & $17 \cdot 4-26 \cdot 3$ & $31 \cdot 3$ & $28.9-33.9$ \\
\hline Autumn & $18 \cdot 6$ & $15 \cdot 3-22 \cdot 4$ & $23 \cdot 2$ & $21 \cdot 2-25 \cdot 4$ \\
\hline Total & $16 \cdot 5$ & $14 \cdot 8-18 \cdot 3$ & $20 \cdot 6$ & $19 \cdot 6-21 \cdot 6$ \\
\hline
\end{tabular}

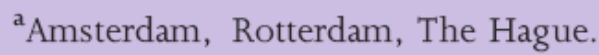


Table 2 Prescriptions in the first contact of episode

\begin{tabular}{|c|c|c|c|c|}
\hline & \multicolumn{2}{|l|}{1987} & \multicolumn{2}{|l|}{2001} \\
\hline & Number & Percentage & Number & Percentage \\
\hline $\begin{array}{l}\text { Total number of } \\
\text { episodes }\end{array}$ & 357 & 100 & 1682 & 100 \\
\hline Oral antibiotic & 109 & 31 & 242 & 14 \\
\hline $\begin{array}{l}\text { Amoxicillin and } \\
\text { other penicillinase- } \\
\text { susceptible penicillins }\end{array}$ & 82 & 23 & 78 & 5 \\
\hline $\begin{array}{l}\text { Penicillinase-resistant } \\
\text { penicillins } \\
\text { (flucloxacillin, amoxicillin }+ \\
\text { clavulanic acid) }\end{array}$ & 15 & 4 & 89 & 5 \\
\hline Macrolides & 4 & 1 & 60 & 4 \\
\hline Cephalosporins & 1 & 0 & 14 & 1 \\
\hline Other & 7 & 2 & 1 & 0 \\
\hline Topical antibiotic & 153 & 43 & 1078 & 64 \\
\hline Fusidic acid & 64 & 18 & 855 & 51 \\
\hline Mupirocin & - & 0 & 210 & 12 \\
\hline Tetracycline & 54 & 15 & 3 & 0 \\
\hline Other & 35 & 10 & 10 & 1 \\
\hline Antiseptic & 40 & 11 & 48 & 3 \\
\hline Chlorhexidine & 12 & 3 & 19 & 1 \\
\hline Povidone-iodine & 17 & 5 & 29 & 2 \\
\hline Other & 11 & 3 & - & 0 \\
\hline Other topical medication & 80 & 22 & 68 & 4 \\
\hline No prescription & 35 & 10 & 240 & 14 \\
\hline
\end{tabular}

\section{REFERENCES}

1. Bruijnzeels MA, van Suijlekom-Smit LWA, van der Velden J, van der Wouden JC. The Child in General Practice. Dutch National Survey of Morbidity and Interventions in General Practice.

Rotterdam: Erasmus Universiteit Rotterdam, 1993

2. van de Lisdonk EH, van den Bosch WJHM, Lagro-Janssen ALM. Ziekten in de Huisartspraktijk. [Diseases in General Practice], 4th edn. Maarssen: Elsevier Gezondheidszorg, 2003.

3. Massa A, Alves R, Amado J et al. Prevalence of cutaneous lesions in Freixo de Espada a Cinta [Portuguese]. Acta Med Port 2000; 13:247- 54.

4. Luby S, Agboatwalla M, Schnell BM et al. The effect of antibacterial soap on impetigo incidence, Karachi, Pakistan. Am J Trop Med Hyg 2002; 67:430-5.

5. Koning S, van Belkum A, Snijders S et al. Severity of nonbullous Staphylococcus aureus impetigo in children is associated with strains harboring genetic markers for exfoliative toxin $B$, PantonValentine leukocidin, and the multidrug resistance plasmid pSK41. J Clin Microbiol 2003; 41:301721.

6. Capoluongo E, Giglio A, Belardi M et al. Association between lesional or nonlesional S. aureus strains from patients with impetigo and exfoliative toxin production. No association with Smal PFGE patterns. New Microbiol 2000; 23:21-7.

7. Afset JE, Maeland JA. Susceptibility of skin and soft-tissue isolates of Staphylococcus aureus and Streptococcus pyogenes to topical antibiotics: indications of clonal spread of fusidic acid-resistant Staphylococcus aureus. Scand J Infect Dis 2003; 35:84-9. 
S. Koning, R.S.A. Mohammedamin, J.C. van der Wouden, L.W.A. van Suijlekom-Smit, F.G. Schellevis, S. Thomas Impetigo: incidence and treatment in Dutch general practice in 1987 and 2001: results from two national surveys. British Journal of Dermatology: jrg. 154, 2006, p. 239-243

8. Brown EM, Wise R. Fusidic acid cream for impetigo. Fusidic acid should be used with restraint. [Comment Letter]. BMJ 2002; 324:1394.

9. Sule O, Brown N, Brown DF et al. Fusidic acid cream for impetigo. Judicious use is advisable. [Comment]. BMJ 2002; 324:1394.

10. Boukes FS, van der Burgh JJ, Nijman FC et al. NHG-Standaard bacterie "le huidinfecties. [Dutch College of General Practitioners' Guideline for bacterial skin infections]. Huisarts Wet 1999; 41: 427-37.

11. Westert GP, Schellevis FG, de Bakker DH et al. Monitoring health inequalities through general practice: the Second Dutch National Survey of General Practice. Eur J Public Health 2005; 15:5965.

12. Tveten $\mathrm{Y}$, Jenkins A, Kristiansen B. A fusidic acid-resistant clone of Staphylococcus aureus associated with impetigo bullosa is spreading in Norway. J Antimicr Chemother 2002; 50:873-6.

13. Laverdiere M, Weiss K, Rivest R, Delorme J. Trends in antibiotic resistance of staphylococci over an eight-year period: differences in the emergence of resistance between coagulase positive and coagulase-negative staphylococci. Microb Drug Resist 1998; 4:119-22.

14. Rortveit S, Rortveit G. An epidemic of bullous impetigo in the municipality of Austevoll in the year 2002. Tidsskr Nor Laegeforen 2003; 123:2557-60.

15. Owen SE, Cheesbrough JS. Fusidic acid cream for impetigo. Findings cannot be extrapolated. [Comment]. BMJ 2002; 324:1394.

16. Statistics Netherlands. Voorburg/Heerlen, 2002 [Webmagazine] Fewer pigs and cows, more milk goats. [updated 12 December 2002]. Available from http://www.cbs.nl/en/publications/articles/ webmagazine/2002/1093k.htm (Accessed 31 March 2005).

17. Aubry-Damon H, Grenet K, Sall-Ndiaye $P$ et al. Antimicrobial resistance in commensal flora of pig farmers. Emerg Infect Dis 2004; 10:873-9.

18. Rao PN, Naidu AS, Rao PR, Rajyalakshmi K. Prevalence of staphylococcal zoonosis in pyogenic skin infections. Zentralbl Bakteriol Mikrobiol Hyg 1987; 265:218-26.

19. Rogers M, Dorman DC, Gapes M, Ly J. A three-year study of impetigo in Sydney. Med J Aust $1987 ; 147: 63-5$.

20. Kristensen JK. Scabies and pyoderma in Lilongwe, Malawi. Prevalence and seasonal fluctuation. Int J Dermatol 1991; 30:699-702.

21. Koning S, Verhagen AP, van Suijlekom-Smit LWA et al. Interventions for Impetigo (Cochrane Review). In: The Cochrane Library, Issue 2. Chichester: John Wiley \& Sons, Ltd. 2004. 